\title{
Excitation Cross Sections for Li-like lons of Beryllium and Boron
}

\author{
A. Starobinets ${ }^{1}$, I. Bray ${ }^{2}$, L. A. Vainshtein ${ }^{3}$, Yu. V. Ralchenko ${ }^{1,4, *}$, and Y. Maron ${ }^{1}$ \\ ${ }^{1}$ Faculty of Physics, Weizmann Institute of Science, Rehovot 76100, Israel \\ ${ }^{2}$ Centre for Atomic, Molecular and Surface Physics, Murdoch University, Perth 6150, Australia \\ ${ }^{3}$ P. N. Lebedev Physical Institute, Russian Academy of Science, Moscow 117924, Russia \\ ${ }^{4}$ Present address: Atomic Physics Division, National Institute of Standards and Technology, Gaithersburg MD 20899-8422, USA
}

Received May 26, 2002; revised version received December 6, 2002; accepted January 7, 2003

PACS Ref: $34.80 . \mathrm{Kw}$

\begin{abstract}
We report on calculation of electron-impact excitation cross sections for Li-like ions of boron and beryllium. The data were produced with a number of modern methods in atomic collision theory, such as convergent close-coupling, K-matrix and Coulomb-Born-exchange. The results obtained are compared with other calculations and available expermental data, and the recommended cross sections for all transitions between atomic terms with principal quantum numbers $n \leq 4$ are presented as tables of fitting parameters.
\end{abstract}

Due to the importance of beryllium and boron for fusion and astrophysics, the collisional data for ions of these elements have often been a subject of research, including calculations of excitation cross sections. The most recent compilation of the recommended data for electron-impact excitation of the $\mathrm{Be}^{q+}$ and $\mathrm{B}^{q+}$ ions [1] was principally based on the R-matrix (RM) and distorted-wave (DW) methods, and included transitions from the ground into the $n=2$ and $n=3$ excited states for all ions. It was found later $[2,3]$ that the accuracy of the calculated RM and DW cross sections, which were used for deriving the recommended data sets for the Li-like ions of beryllium and boron, may be inferior to that of the recently developed methods, such as the convergent close-coupling (CCC) and the R-matrix with pseudostates (RMPS). The disagreement was found to be especially noticeable for the intermediate energy region, where the coupling with the continuum states is important, and hence the applicability of the recommended data [1] may be limited. In addition, as has been noted above, transitions between excited states were not considered in Ref. [1]. It has to be mentioned that the cross sections for the transitions between excited states can only rarely be found in the literature, although they may be very important for applications. This can be exemplified by the experiment on laser pumping of specific atomic levels [4], where such transitions crucially affect the measured light emission. Thus, it seems appropriate to produce a new set of highaccuracy excitation data for the Li-like ions of boron and beryllium, including transitions between excited states.

The non-perturbative close-coupling (CC) type methods, which are known to provide the highest accuracy among the existing theoretical approaches, normally require significant computational efforts, in terms of both hardware requirements and computation times. This justifies development of simpler and faster, yet sufficiently accurate, methods which

\footnotetext{
*E-mail: fnralch@plasma-gate.weizmann.ac.il
}

could be of practical use with widely available computational tools. As for the highly-charged $\mathrm{H}$ - and Li-like ions, it was already shown $[5,6]$ that the first-order Coulomb-Bornexchange method (CBE) with normalization on one channel can be reliably applied to the calculation of the excitation cross sections for ions with a large spectroscopic charge $(Z \geq 3)$. For the low-charge ions, however, the channel interaction effects, which are ignored within the CBE approximation, become more important and thus require application of the CC type approaches for an accurate calculation of the cross sections.

In the present paper the electron-impact excitation cross sections for all $n l-n^{\prime} l^{\prime}(n=2, \ldots, 4, l=0, \ldots, n-1)$ transitions in the Li-like Be II and B III ions** are calculated with a number of different methods in the electron-ion scattering theory, and the recommended sets of data are tabulated as fitting parameters for the functions having correct asymptotic behavior of cross sections. This allows a direct use of the results presented here for practical needs, e.g., for plasma kinetics calculations. Specifically, our recommendations are principally derived from the data produced with the CCC method that has shown high accuracy for various few-electron ions. Besides, in order to investigate the accuracy of the recently developed AKM code which is based on the K-matrix approximation [8], the same set of excitation cross sections is calculated with this new code and compared with the CCC and other, including CBE and RMPS, data.

Since the CCC approach has already been a subject of many comprehensive reviews, we refer the reader to, e.g., Refs. [9] and [10] and references therein for a detailed discussion on its basic features. Similarly, the CBE approximation is well described in Refs. [11,12] and is not discussed below.

The K-matrix method in its modification of Ref. [8] was developed recently and therefore is outlined here. This technique is based on the first order CBE calculation of the matrix $\boldsymbol{K}$ for a given set of transitions. The excitation cross section $\sigma\left(a_{0}-a_{1}\right)$ between atomic states $a_{0}$ and $a_{1}$ is given by:

$$
\begin{aligned}
\sigma\left(a_{0}-a_{1} \mid K\right)= & \frac{1}{E} \sum \frac{\left[S_{T} L_{T}\right]^{2}}{2\left[S_{0} L_{0}\right]^{2}} \\
& \times\left|S\left(\Gamma_{0}, \Gamma_{1} \mid K\right)-I\left(\Gamma_{0}, \Gamma_{1}\right)\right|^{2}
\end{aligned}
$$

\footnotetext{
** The recommended data for neutral $\mathrm{Li}$, calculated with the CCC method, can be found in Ref. [7].
} 
where $E$ is the electron impact energy, $S_{0}\left(L_{0}\right)$ is the spin (orbital) angular momentum of $a_{0}$, and $S_{T}\left(L_{T}\right)$ is the total spin (orbital) angular momentum. The quantity $\Gamma=a \varepsilon \lambda S_{T} L_{T}$ is the set of all quantum numbers for the ion-electron system, with $\varepsilon$ being the electron energy $\left(\varepsilon_{0}=E\right)$, and $\lambda$ being the free-electron orbital angular momentum. Obviously, $\quad \boldsymbol{S}_{T}=\boldsymbol{S}_{0}+\boldsymbol{s}=\boldsymbol{S}_{1}+\boldsymbol{s}, \quad \boldsymbol{L}_{T}=$ $\boldsymbol{L}_{0}+\lambda_{0}=\boldsymbol{L}_{1}+\lambda_{1}$ where $s=1 / 2$ is the free electron spin. Finally, $S\left(\Gamma_{0}, \Gamma_{1} \mid K\right)$ is the $S$ matrix, which is calculated with the Coulomb-Born $\boldsymbol{K}$ matrix via

$\mathbf{S}=\frac{\boldsymbol{I}+\mathrm{i} \boldsymbol{K}}{\boldsymbol{I}-\mathrm{i} \boldsymbol{K}}$

and $I\left(\Gamma_{0}, \Gamma_{1}\right)$ is the unity matrix.

The elements of the CBE $\boldsymbol{K}$ matrix $\left(a=a_{c}\left[S_{c} L_{c}\right] n l S L\right.$, $a^{\prime}=a_{c}\left[S_{c} L_{c}\right] n^{\prime} l^{\prime} S^{\prime} L^{\prime}$, where the subscript $c$ denotes parameters related to the atomic core) are calculated with the well-known expressions

$K\left(\Gamma, \Gamma^{\prime}\right)=\sum_{\kappa} K_{\kappa}\left(\Gamma, \Gamma^{\prime}\right)$

with

$$
\begin{aligned}
K_{\kappa}\left(\Gamma, \Gamma^{\prime}\right) & =\left(R_{\kappa}^{d}-B_{S S^{\prime}} R_{\kappa}^{\prime \prime}\right) A_{\kappa}\left(L L^{\prime} L_{T}\right), \\
B_{S S^{\prime}} & =\left[S S^{\prime}\right]\left\{\begin{array}{ccc}
\frac{1}{2} & S & S_{T} \\
\frac{1}{2} & S^{\prime} & S_{c}
\end{array}\right\}(-1)^{1-S-S^{\prime}}, \\
A_{\kappa}\left(L L^{\prime} L_{T}\right) & =\left[L L^{\prime}\right]\left\{\begin{array}{lll}
L & L^{\prime} & \kappa \\
l^{\prime} & l & L_{c}
\end{array}\right\}\left\{\begin{array}{lll}
L & L^{\prime} & \kappa \\
\lambda^{\prime} & \lambda & L_{T}
\end{array}\right\}(-1)^{L_{T}+L+L^{\prime}} .
\end{aligned}
$$

Here $R_{\kappa}^{d}$ and $R_{\kappa}$ are the direct and exchange radial integrals and the exchange contribution is calculated with the orthogonalized functions method [11].

In the present version of $\mathrm{K}$-matrix method we omit the diagonal matrix elements which corresponds to the Born rather than distorted wave basis. Although the latter approach takes into account the attraction of the external electron to the ion, however, for inelastic collisions it is the distance to the optical electron that is important, and due to the repulsion between electrons this distance increases. It is well known that usually the first Born approximation

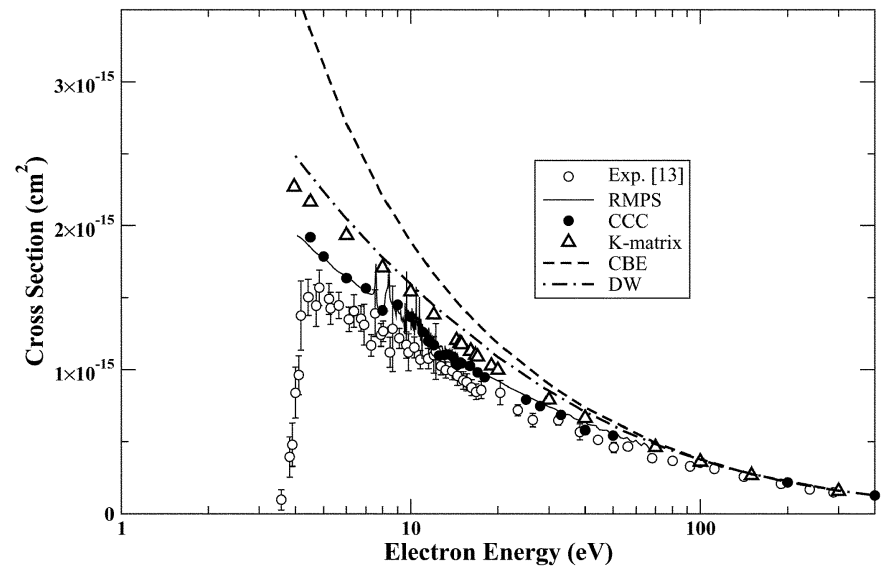

Fig. 1. Excitation cross section $2 \mathrm{~s}-2 \mathrm{p}$ in Be II. Experiment [13] - open circles, RMPS [2] - solid line; CCC — solid circles; KM—open triangles; $\mathrm{CBE}$ — dashed line; DW [1] — dash-dotted line.

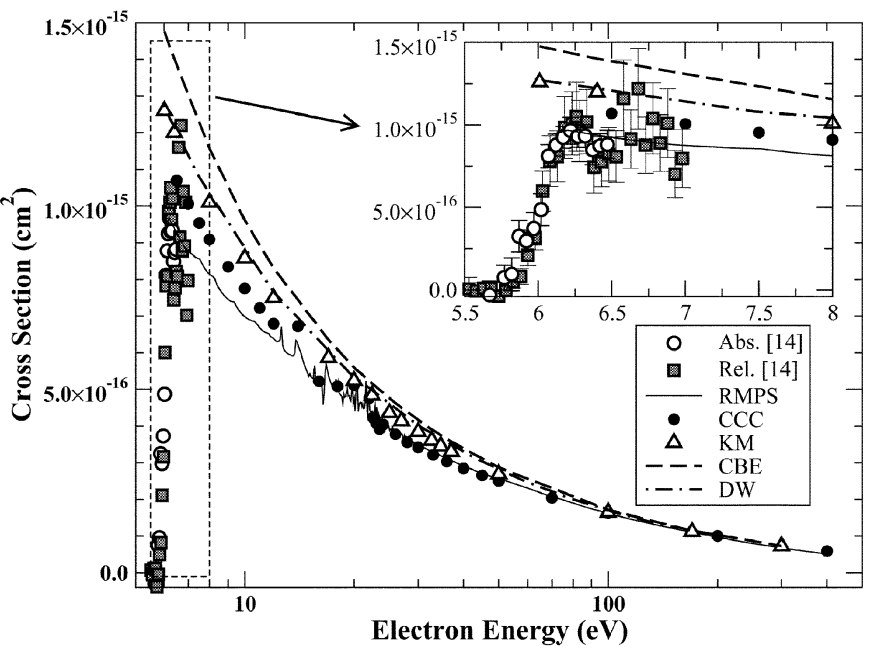

Fig. 2. Excitation cross section $2 s-2 p$ in B III. Experiment [14]shadowed squares (relative measurements) and open circles (absolute measurements), RMPS [2] - solid line; CCC - solid circles; KM-open triangles; $\mathrm{CBE}$ - dashed line; DW [1] — dash-dotted line. The near-threshold region is enlarged in the insert.

overestimates cross section, therefore the repulsion ("polarization of the atom") effect exceeds the distorted wave one.

The K-matrix cross sections calculated from Eqs. (1)-(4) have the following advantages: $(i)$ they are normalized, i.e. the sums of the partial cross sections over the channels included do not exceed the theoretical unitarity limit, and (ii) the channel interaction is approximately included, in particular the transitions through intermediate virtual states become possible. For more details on this method the reader is referred to Ref. [11].

Similar to [2] and [3], where the excitations from the ground state only were investigated, here the CCC cross sections are calculated with account of the $14 \mathrm{~S}, 14 \mathrm{P}, 13 \mathrm{D}$, $12 \mathrm{~F}$ and $11 \mathrm{G}$ states. Diagonalization of the target Hamiltonian in a large Laguerre basis ensures that the lower bound states accurately represent the true physical target states $1 \mathrm{~s}^{2} n l^{2} \mathrm{~L}$ up to $n=5$. The K-matrix calculations with the AKM code were carried out with account of all atomic terms $1 \mathrm{~s}^{2} n l^{2} \mathrm{~L}$ up to the principal quantum number $n=6$, i.e., total of 20 states. The typical AKM runtime on a moderate-level PC was about half an hour for all cross sections for either of the ions involved, and the CCC computation times on the same PC are more than

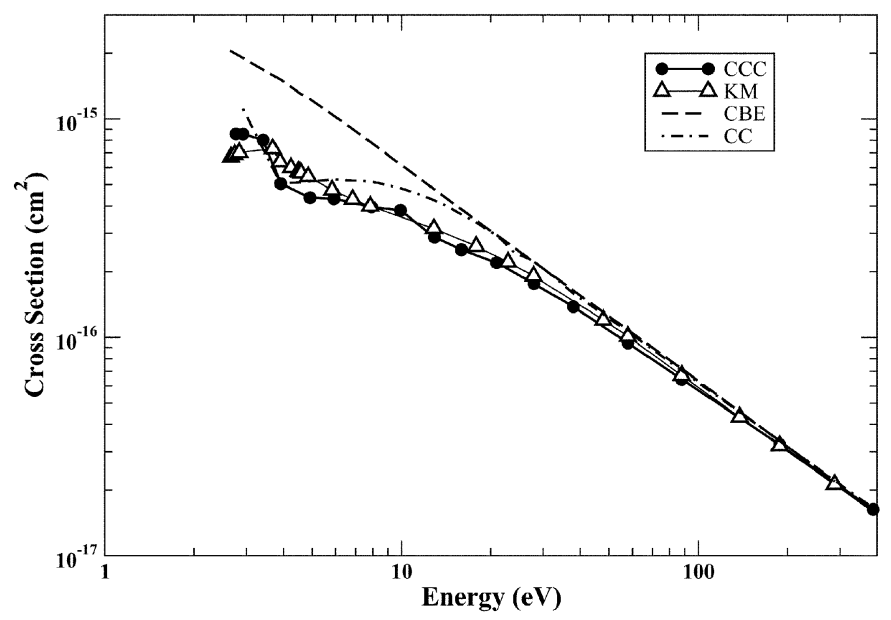

Fig. 3. Excitation cross section 3d-4d in Be II. CCC-solid circles; KMopen triangles; $\mathrm{CBE}$ - dashed line; $\mathrm{CC}$ - dash-dotted line. 


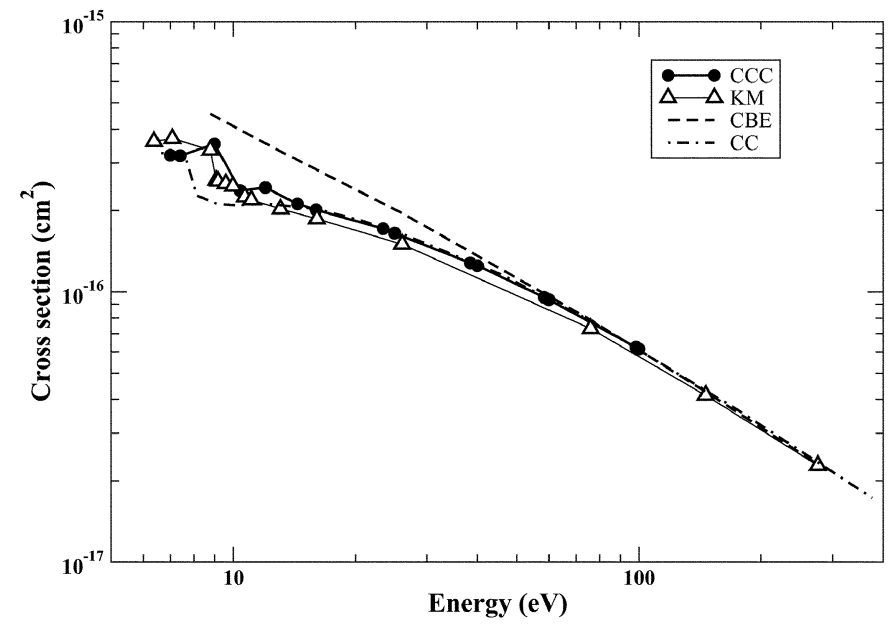

Fig. 4. Excitation cross section 3p-4f in B III. CCC-solid circles; KMopen triangles; $\mathrm{CBE}$ - dashed line; $\mathrm{CC}$ - dash-dotted line.

two orders of magnitude larger. The numerical AKM data can be retrieved from the URL http://plasma-gate.weizmann.ac.il/KM/Li_like/.

In addition to the $\mathrm{CCC}, \mathrm{CBE}$ and $\mathrm{K}$-matrix methods, the excitation cross sections were also calculated by the standard close-coupling (CC) method with no account of the pseudostates. In this approximation, the ionization channels are in fact eliminated from the close-coupling expansion. It was found that in the majority of cases the $\mathrm{CC}$ cross sections exceed the CCC ones in the intermediate energy range. This effect is obviously due to lack of the particle flux into the open channels in the CC approach. Note that for most transitions the CBE method also overestimates the cross sections. It is well known that the Coulomb-Born method corresponds to the $1 / Z$ perturbation theory, and therefore may not be very accurate for the low-charge ions. For example, for the $\Delta n=0, n \mathrm{~s}-n \mathrm{p}$ transitions with $n=3$ and 4 , the CBE results at the energy threshold exceed both the CCC and the KM cross sections by a factor of about 4 and 10, respectively. This specific case demonstrates the importance of a strong normalization effect, which is not intrinsically present in the CBE method but is automatically accounted for in the $\mathrm{CC}$ and CCC equations.

A comparison with experimental data is largely impeded by a lack of comprehensive measurements. Although the number of theoretical publications on excitation of Li-like ions of beryllium and boron is quite significant, the only available experimental cross sections for Be II [13] and B III [14] were measured for the resonance excitation $2 s-2 p$, for the latter only the near-threshold region having been investigated so far. Figures 1 and 2 show these data and the presently calculated cross sections and earlier calculations by the RMPS and DW methods.

Table I. Fitting coefficients for the electron-impact excitation cross sections in Be II.

\begin{tabular}{|c|c|c|c|c|c|c|c|}
\hline Low & Upp & Eq. & $A_{1}$ & $A_{2}$ & $A_{3}$ & $A_{4}$ & $A_{5}$ \\
\hline $2 \mathrm{~s}$ & $2 p$ & 5 & $4.544 \mathrm{E}-19$ & $1.715 \mathrm{E}-15$ & $1.773 E-15$ & $-1.638 \mathrm{E}-15$ & $2.637 \mathrm{E}-15$ \\
\hline $2 \mathrm{~s}$ & $3 \mathrm{~s}$ & 6 & $8.122 \mathrm{E}-17$ & $-1.664 \mathrm{E}-16$ & $1.001 E-16$ & $-3.300 \mathrm{E}-01$ & $1.000 \mathrm{E}+00$ \\
\hline $2 \mathrm{~s}$ & $3 p$ & 5 & $-5.370 \mathrm{E}-17$ & $9.079 \mathrm{E}-17$ & $6.833 E-19$ & $-5.370 \mathrm{E}-18$ & $4.088 \mathrm{E}-17$ \\
\hline $2 s$ & $3 d$ & 6 & $1.668 \mathrm{E}-16$ & $3.454 \mathrm{E}-16$ & $3.248 \mathrm{E}-16$ & $1.199 \mathrm{E}+00$ & $1.000 \mathrm{E}+00$ \\
\hline $2 s$ & $4 s$ & 6 & $1.018 \mathrm{E}-17$ & $-2.106 \mathrm{E}-17$ & $1.214 \mathrm{E}-17$ & $-4.141 \mathrm{E}-01$ & $1.000 \mathrm{E}+00$ \\
\hline $2 \mathrm{~s}$ & $4 p$ & 5 & $-3.246 \mathrm{E}-17$ & $9.418 \mathrm{E}-17$ & $-1.100 \mathrm{E}-16$ & $5.996 \mathrm{E}-17$ & $1.616 \mathrm{E}-17$ \\
\hline $2 s$ & $4 d$ & 6 & $3.509 \mathrm{E}-17$ & $8.230 \mathrm{E}-17$ & $9.230 \mathrm{E}-17$ & $1.412 \mathrm{E}+00$ & $1.000 \mathrm{E}+00$ \\
\hline $2 s$ & $4 \mathrm{f}$ & 6 & $6.800 \mathrm{E}-18$ & $-1.332 \mathrm{E}-17$ & $6.805 E-18$ & $-5.756 \mathrm{E}-01$ & $1.000 \mathrm{E}+00$ \\
\hline $2 \mathrm{p}$ & $3 \mathrm{~s}$ & 5 & $3.500 \mathrm{E}-19$ & $-2.327 \mathrm{E}-16$ & $4.644 \mathrm{E}-16$ & $-1.449 \mathrm{E}-16$ & $8.002 \mathrm{E}-17$ \\
\hline $2 p$ & $3 p$ & 6 & $2.128 \mathrm{E}-16$ & $-3.968 \mathrm{E}-16$ & $4.807 \mathrm{E}-16$ & $1.327 \mathrm{E}-01$ & $1.000 \mathrm{E}+00$ \\
\hline $2 \mathrm{p}$ & $3 d$ & 5 & $1.136 \mathrm{E}-18$ & $-1.715 \mathrm{E}-15$ & $4.098 \mathrm{E}-15$ & $-2.255 \mathrm{E}-15$ & $6.008 \mathrm{E}-16$ \\
\hline $2 p$ & $4 \mathrm{~s}$ & 5 & $8.680 \mathrm{E}-19$ & $3.364 \mathrm{E}-18$ & $-1.613 \mathrm{E}-17$ & $2.443 \mathrm{E}-17$ & $5.598 \mathrm{E}-18$ \\
\hline $2 \mathrm{p}$ & $4 p$ & 6 & $2.828 \mathrm{E}-17$ & $-5.664 \mathrm{E}-17$ & $3.617 \mathrm{E}-17$ & $-3.025 \mathrm{E}-01$ & $1.000 \mathrm{E}+00$ \\
\hline $2 \mathrm{p}$ & $4 d$ & 5 & $8.846 \mathrm{E}-19$ & $-1.175 \mathrm{E}-16$ & $2.598 \mathrm{E}-16$ & $-1.153 \mathrm{E}-16$ & $7.794 \mathrm{E}-17$ \\
\hline $2 \mathrm{p}$ & $4 \mathrm{f}$ & 6 & $3.677 \mathrm{E}-17$ & $-5.412 \mathrm{E}-17$ & $4.042 \mathrm{E}-17$ & $-4.146 \mathrm{E}-02$ & $1.000 \mathrm{E}+00$ \\
\hline $3 \mathrm{~s}$ & $3 p$ & 5 & $-6.497 \mathrm{E}-14$ & $5.372 \mathrm{E}-14$ & $1.048 \mathrm{E}-13$ & $-7.218 \mathrm{E}-14$ & $7.207 \mathrm{E}-14$ \\
\hline $3 \mathrm{~s}$ & $3 d$ & 6 & $1.414 \mathrm{E}-14$ & $-2.555 \mathrm{E}-14$ & $5.666 \mathrm{E}-13$ & $1.720 \mathrm{E}+00$ & $1.000 \mathrm{E}+00$ \\
\hline $3 \mathrm{~s}$ & $4 \mathrm{~s}$ & 6 & $1.500 \mathrm{E}-15$ & $-2.100 \mathrm{E}-15$ & $1.500 \mathrm{E}-15$ & $2.000 \mathrm{E}-01$ & $1.000 \mathrm{E}+00$ \\
\hline $3 \mathrm{~s}$ & $4 p$ & 5 & $-2.655 \mathrm{E}-16$ & $5.378 \mathrm{E}-16$ & $1.589 \mathrm{E}-16$ & $-1.427 \mathrm{E}-16$ & $2.923 \mathrm{E}-16$ \\
\hline $3 \mathrm{~s}$ & $4 d$ & 6 & $1.108 \mathrm{E}-15$ & $-1.783 \mathrm{E}-15$ & $1.029 E-15$ & $1.131 \mathrm{E}-02$ & $1.000 \mathrm{E}+00$ \\
\hline $3 \mathrm{~s}$ & $4 f$ & 6 & $1.209 \mathrm{E}-15$ & $-1.952 \mathrm{E}-15$ & $1.143 \mathrm{E}-15$ & $-1.039 \mathrm{E}-01$ & $1.000 \mathrm{E}+00$ \\
\hline $3 p$ & $3 d$ & 5 & $2.986 \mathrm{E}-20$ & $-3.459 \mathrm{E}-14$ & $8.789 E-13$ & $-6.201 \mathrm{E}-13$ & $1.952 \mathrm{E}-13$ \\
\hline $3 p$ & $4 \mathrm{~s}$ & 5 & $-3.746 \mathrm{E}-15$ & $6.327 \mathrm{E}-15$ & $-2.798 \mathrm{E}-15$ & $4.632 \mathrm{E}-16$ & $2.213 \mathrm{E}-15$ \\
\hline $3 p$ & $4 p$ & 6 & $2.527 \mathrm{E}-15$ & $-5.310 \mathrm{E}-15$ & $4.355 \mathrm{E}-15$ & $1.510 \mathrm{E}-01$ & $1.000 \mathrm{E}+00$ \\
\hline $3 p$ & $4 d$ & 5 & $-8.906 \mathrm{E}-15$ & $1.133 \mathrm{E}-14$ & $3.674 \mathrm{E}-15$ & $-5.420 \mathrm{E}-15$ & $5.717 \mathrm{E}-15$ \\
\hline $3 p$ & $4 \mathrm{f}$ & 6 & $5.786 \mathrm{E}-15$ & $-9.615 E-15$ & $1.213 \mathrm{E}-14$ & $7.254 \mathrm{E}-01$ & $1.000 \mathrm{E}+00$ \\
\hline $3 d$ & $4 \mathrm{~s}$ & 6 & $2.403 \mathrm{E}-16$ & $-3.629 \mathrm{E}-16$ & $7.217 \mathrm{E}-16$ & $2.824 \mathrm{E}-01$ & $1.000 \mathrm{E}+00$ \\
\hline $3 d$ & $4 \mathrm{p}$ & 5 & $-2.221 \mathrm{E}-16$ & $1.554 \mathrm{E}-15$ & $-1.665 \mathrm{E}-15$ & $1.049 \mathrm{E}-15$ & $2.107 \mathrm{E}-16$ \\
\hline $3 d$ & $4 d$ & 6 & $2.344 \mathrm{E}-15$ & $-3.949 E-15$ & $3.543 E-15$ & $1.681 \mathrm{E}-01$ & $1.000 \mathrm{E}+00$ \\
\hline $3 d$ & $4 \mathrm{f}$ & 5 & $-3.674 \mathrm{E}-15$ & $-2.024 \mathrm{E}-14$ & $5.907 \mathrm{E}-14$ & $-3.356 \mathrm{E}-14$ & $8.760 \mathrm{E}-15$ \\
\hline $4 s$ & $4 p$ & 5 & $-1.395 \mathrm{E}-12$ & $2.678 \mathrm{E}-12$ & $-1.699 \mathrm{E}-12$ & $4.792 \mathrm{E}-13$ & $7.700 \mathrm{E}-13$ \\
\hline $4 \mathrm{~s}$ & $4 d$ & 6 & $9.646 \mathrm{E}-14$ & $5.217 \mathrm{E}-13$ & $1.715 \mathrm{E}-12$ & $1.494 \mathrm{E}+00$ & $1.000 \mathrm{E}+00$ \\
\hline $4 s$ & $4 \mathrm{f}$ & 6 & $2.087 \mathrm{E}-14$ & $-7.872 \mathrm{E}-14$ & $1.121 \mathrm{E}-12$ & $1.608 \mathrm{E}+00$ & $1.000 \mathrm{E}+00$ \\
\hline $4 p$ & $4 d$ & 5 & $5.443 \mathrm{E}-26$ & $-9.999 E-22$ & $3.051 \mathrm{E}-21$ & $-1.902 \mathrm{E}-21$ & $1.455 \mathrm{E}-12$ \\
\hline $4 p$ & $4 f$ & 6 & $2.158 \mathrm{E}-13$ & $2.564 \mathrm{E}-14$ & $-1.980 \mathrm{E}-13$ & $-3.081 \mathrm{E}-01$ & $1.000 \mathrm{E}+00$ \\
\hline $4 d$ & $4 \mathrm{f}$ & 5 & $1.000 \mathrm{E}-11$ & $-9.999 E-22$ & $3.051 \mathrm{E}-21$ & $-1.902 \mathrm{E}-21$ & $2.840 \mathrm{E}-11$ \\
\hline
\end{tabular}


Table II. Fitting coefficients for the electron-impact excitation cross sections in B III.

\begin{tabular}{|c|c|c|c|c|c|c|c|}
\hline Low & Upp & Eq. & $A_{1}$ & $A_{2}$ & $A_{3}$ & $A_{4}$ & $A_{5}$ \\
\hline $2 \mathrm{~s}$ & $2 \mathrm{p}$ & 5 & $-4.263 \mathrm{E}-19$ & $2.059 \mathrm{E}-15$ & $-1.934 \mathrm{E}-15$ & $8.601 E-16$ & $9.026 \mathrm{E}-16$ \\
\hline $2 \mathrm{~s}$ & $3 \mathrm{~s}$ & 6 & $1.850 \mathrm{E}-17$ & $-3.903 \mathrm{E}-17$ & $2.313 \mathrm{E}-17$ & $-4.124 \mathrm{E}-01$ & $1.000 \mathrm{E}+00$ \\
\hline $2 \mathrm{~s}$ & $3 p$ & 5 & $-2.732 \mathrm{E}-17$ & $6.708 \mathrm{E}-17$ & $-7.946 \mathrm{E}-17$ & $5.285 \mathrm{E}-17$ & $1.942 \mathrm{E}-17$ \\
\hline $2 \mathrm{~s}$ & $3 d$ & 6 & $5.347 \mathrm{E}-17$ & $-7.745 \mathrm{E}-17$ & $5.450 \mathrm{E}-17$ & $1.713 \mathrm{E}-01$ & $1.000 \mathrm{E}+00$ \\
\hline $2 \mathrm{~s}$ & $4 \mathrm{~s}$ & 6 & $2.822 \mathrm{E}-18$ & $-5.259 \mathrm{E}-18$ & $2.969 \mathrm{E}-18$ & $-2.949 \mathrm{E}-01$ & $1.000 \mathrm{E}+00$ \\
\hline $2 \mathrm{~s}$ & $4 p$ & 5 & $-3.020 \mathrm{E}-18$ & $5.073 \mathrm{E}-18$ & $-1.856 \mathrm{E}-18$ & $2.503 \mathrm{E}-18$ & $3.576 \mathrm{E}-18$ \\
\hline $2 \mathrm{~s}$ & $4 d$ & 6 & $8.769 \mathrm{E}-18$ & $-1.177 \mathrm{E}-17$ & $9.020 \mathrm{E}-18$ & $2.585 \mathrm{E}-01$ & $1.000 \mathrm{E}+00$ \\
\hline $2 \mathrm{~s}$ & $4 f$ & 6 & $1.900 \mathrm{E}-18$ & $-3.655 \mathrm{E}-18$ & $1.923 \mathrm{E}-18$ & $-5.193 \mathrm{E}-01$ & $1.000 \mathrm{E}+00$ \\
\hline $2 \mathrm{p}$ & $3 \mathrm{~s}$ & 5 & $-2.834 \mathrm{E}-17$ & $9.799 \mathrm{E}-17$ & $-1.507 \mathrm{E}-16$ & $9.844 \mathrm{E}-17$ & $1.638 \mathrm{E}-17$ \\
\hline $2 \mathrm{p}$ & $3 p$ & 6 & $3.225 \mathrm{E}-17$ & $-5.649 \mathrm{E}-17$ & $3.518 \mathrm{E}-17$ & $-2.773 \mathrm{E}-01$ & $1.000 \mathrm{E}+00$ \\
\hline $2 \mathrm{p}$ & $3 d$ & 5 & $-4.907 \mathrm{E}-17$ & $5.475 \mathrm{E}-17$ & $8.412 \mathrm{E}-17$ & $-2.261 \mathrm{E}-17$ & $1.346 \mathrm{E}-16$ \\
\hline $2 \mathrm{p}$ & $4 \mathrm{~s}$ & 5 & $2.156 \mathrm{E}-19$ & $-1.755 \mathrm{E}-18$ & $5.760 \mathrm{E}-18$ & $-2.881 \mathrm{E}-18$ & $8.500 \mathrm{E}-19$ \\
\hline $2 \mathrm{p}$ & $4 p$ & 6 & $6.215 \mathrm{E}-18$ & $-1.009 \mathrm{E}-17$ & $8.774 \mathrm{E}-18$ & $-3.939 E-02$ & $1.000 \mathrm{E}+00$ \\
\hline $2 \mathrm{p}$ & $4 d$ & 5 & $2.059 \mathrm{E}-17$ & $-7.944 \mathrm{E}-17$ & $1.247 \mathrm{E}-16$ & $-5.737 \mathrm{E}-17$ & $1.071 \mathrm{E}-17$ \\
\hline $2 \mathrm{p}$ & $4 \mathrm{f}$ & 6 & $6.973 \mathrm{E}-18$ & $-1.334 \mathrm{E}-17$ & $7.871 \mathrm{E}-18$ & $-3.372 \mathrm{E}-01$ & $1.000 \mathrm{E}+00$ \\
\hline $3 \mathrm{~s}$ & $3 p$ & 5 & $5.443 \mathrm{E}-26$ & $5.095 \mathrm{E}-16$ & $3.282 \mathrm{E}-14$ & $-1.191 \mathrm{E}-14$ & $1.900 \mathrm{E}-14$ \\
\hline $3 \mathrm{~s}$ & $3 d$ & 6 & $3.315 \mathrm{E}-15$ & $7.024 \mathrm{E}-16$ & $1.196 \mathrm{E}-16$ & $-2.080 \mathrm{E}-02$ & $1.000 \mathrm{E}+00$ \\
\hline $3 \mathrm{~s}$ & $4 \mathrm{~s}$ & 6 & $3.279 \mathrm{E}-16$ & $-1.439 E-16$ & $5.643 \mathrm{E}-16$ & $4.380 \mathrm{E}-01$ & $1.000 \mathrm{E}+00$ \\
\hline $3 \mathrm{~s}$ & $4 p$ & 5 & $-2.219 \mathrm{E}-16$ & $2.736 \mathrm{E}-16$ & $2.986 \mathrm{E}-16$ & $-2.951 \mathrm{E}-16$ & $1.609 E-16$ \\
\hline $3 \mathrm{~s}$ & $4 d$ & 6 & $3.265 \mathrm{E}-16$ & $-4.085 \mathrm{E}-16$ & $2.196 \mathrm{E}-16$ & $3.533 \mathrm{E}-02$ & $1.000 \mathrm{E}+00$ \\
\hline $3 \mathrm{~s}$ & $4 \mathrm{f}$ & 6 & $2.958 \mathrm{E}-16$ & $1.555 \mathrm{E}-16$ & $-9.492 \mathrm{E}-17$ & $1.982 \mathrm{E}-01$ & $1.000 \mathrm{E}+00$ \\
\hline $3 p$ & $3 d$ & 5 & $5.443 \mathrm{E}-26$ & $5.850 \mathrm{E}-14$ & $1.850 \mathrm{E}-13$ & $-1.521 \mathrm{E}-13$ & $4.533 \mathrm{E}-14$ \\
\hline $3 p$ & $4 \mathrm{~s}$ & 5 & $-6.379 E-16$ & $1.376 \mathrm{E}-15$ & $-1.025 \mathrm{E}-15$ & $3.229 \mathrm{E}-16$ & $3.406 \mathrm{E}-16$ \\
\hline $3 p$ & $4 p$ & 6 & $5.393 \mathrm{E}-16$ & $-6.951 \mathrm{E}-16$ & $1.074 \mathrm{E}-15$ & $4.120 \mathrm{E}-01$ & $1.000 \mathrm{E}+00$ \\
\hline $3 p$ & $4 d$ & 5 & $-1.127 \mathrm{E}-15$ & $1.324 \mathrm{E}-15$ & $1.358 \mathrm{E}-15$ & $-1.335 \mathrm{E}-15$ & $9.629 \mathrm{E}-16$ \\
\hline $3 p$ & $4 \mathrm{f}$ & 6 & $1.091 \mathrm{E}-15$ & $-2.201 \mathrm{E}-16$ & $1.352 \mathrm{E}-15$ & $5.839 \mathrm{E}-01$ & $1.000 \mathrm{E}+00$ \\
\hline $3 d$ & $4 \mathrm{~s}$ & 6 & $3.611 \mathrm{E}-17$ & $-4.467 \mathrm{E}-17$ & $3.252 \mathrm{E}-16$ & $6.968 \mathrm{E}-01$ & $1.000 \mathrm{E}+00$ \\
\hline $3 d$ & $4 p$ & 5 & $1.300 \mathrm{E}-16$ & $-5.886 \mathrm{E}-16$ & $1.487 \mathrm{E}-15$ & $-9.176 \mathrm{E}-16$ & $9.500 \mathrm{E}-19$ \\
\hline $3 d$ & $4 d$ & 6 & $5.623 \mathrm{E}-16$ & $-4.538 \mathrm{E}-16$ & $5.021 \mathrm{E}-15$ & $1.116 \mathrm{E}+00$ & $1.000 \mathrm{E}+00$ \\
\hline $3 d$ & $4 \mathrm{f}$ & 5 & $5.443 \mathrm{E}-26$ & $-5.521 \mathrm{E}-15$ & $1.629 \mathrm{E}-14$ & $-1.029 \mathrm{E}-14$ & $1.801 \mathrm{E}-15$ \\
\hline $4 s$ & $4 p$ & 5 & $5.443 \mathrm{E}-26$ & $-5.108 \mathrm{E}-13$ & $1.353 \mathrm{E}-12$ & $-7.831 \mathrm{E}-13$ & $1.413 \mathrm{E}-13$ \\
\hline $4 s$ & $4 \mathrm{~d}$ & 6 & $3.442 \mathrm{E}-14$ & $-2.683 E-14$ & $4.239 \mathrm{E}-15$ & $-2.203 \mathrm{E}-01$ & $1.000 \mathrm{E}+00$ \\
\hline $4 s$ & $4 \mathrm{f}$ & 6 & $4.739 E-15$ & $5.627 \mathrm{E}-15$ & $-8.206 \mathrm{E}-15$ & $-1.966 \mathrm{E}-01$ & $1.000 \mathrm{E}+00$ \\
\hline $4 p$ & $4 d$ & 5 & $5.443 \mathrm{E}-26$ & $-9.973 E-13$ & $3.876 \mathrm{E}-12$ & $-2.612 \mathrm{E}-12$ & $3.607 \mathrm{E}-13$ \\
\hline $4 p$ & $4 \mathrm{f}$ & 6 & $5.817 \mathrm{E}-14$ & $2.375 E-13$ & $-1.914 \mathrm{E}-13$ & $2.958 \mathrm{E}-01$ & $1.000 \mathrm{E}+00$ \\
\hline $4 d$ & $4 \mathrm{f}$ & 5 & $1.000 \mathrm{E}-11$ & $1.185 \mathrm{E}-18$ & $9.793 E-19$ & $3.102 E-18$ & $4.998 \mathrm{E}-12$ \\
\hline
\end{tabular}

As one can see from Fig. 1, the advanced theoretical methods (CCC and RMPS) agree very well for the Be II case in the whole energy range. However, the experimental data of Ref. [13] are consistently lower by about $15 \%$ for the low and moderate energies although the high-energy experimental asymptotics seems to converge to the theoretical curves. The first-order CBE method overestimates the cross section at the threshold $(\Delta E=3.96 \mathrm{eV})$ by as much as a factor of two, which does not seem surprising for this low-charge ion. The present K-matrix results are seen to agree much better with the CCC/RMPS data so that the difference is less than $20 \%$ near the threshold and improves towards higher energies. For this strong dipole-allowed transition, the DW data are quite close to the $\mathrm{K}$-matrix results, and this is the case also for the B III $2 s-2 p$ transition (Fig. 2). For this ion, the RMPS results were found to excellently agree with the recent near-threshold $(\Delta E=6.00 \mathrm{eV})$ experimental data [14]. The open circles and shadowed squares on the plot represent the absolute and relative measurements, respectively (see Ref. [14] for more details). The calculated CCC cross sections are, however, about $10 \%$ higher than the RMPS although still being within experimental error bars. Again, as for the Be II case, the K-matrix results show improvement comparing to the $\mathrm{CBE}$ data which are now about $50 \%$ higher than experiment near the threshold (cf. higher ion charge for B III). Finally, it has to be mentioned that the effect of pseudostates is not significant for the strong resonance $2 \mathrm{~s}-2 \mathrm{p}$ transition, and thus the $\mathrm{CC}$ results practically do not differ from the $\mathrm{CCC}$ ones for both ions. Therefore, the $\mathrm{CC}$ data are not presented on Figs. 1 and 2.

As for the other transitions, including those between the excited states, the K-matrix results are found to generally be much closer to the CCC data in terms of both the absolute values and the shapes of the cross sections, the difference normally being within $20-30 \%$ for the former. Typical examples of calculated data are shown in Figs. 3 and 4, where the dipole-forbidden excitation cross sections for the transitions $3 \mathrm{~d}-4 \mathrm{~d}$ in $\mathrm{Be}$ II and $3 \mathrm{p}-4 \mathrm{f}$ in $\mathrm{B}$ III are presented, respectively. It is clearly seen that the $\mathrm{CBE}$ data exceed the other results in the near-threshold and intermediate-energy regions. Besides, since the CBE method does not include the channel interaction, the resonance features in the cross sections above the energy threshold are not reproduced within this approximation. On the other hand, the $\mathrm{K}$ matrix cross sections agree very well with the CCC data at all energies for both cases. Finally, the CC $3 d-4 d$ results in Fig. 3 are seen to exceed the full convergent close-coupling data in the intermediate energy range, while for the $3 p-4 f$ cross section in B III (Fig. 4) the difference between $\mathrm{CC}$ and $\mathrm{CCC}$ is more prominent near the threshold. 
The CCC excitation cross sections for the transitions $n l-n^{\prime} l^{\prime}$ were fitted with the following formulas:

$$
\begin{aligned}
& \sigma_{d a}(x)=\frac{A_{1}}{x}+\frac{A_{2}}{x^{2}}+\frac{A_{3}}{x^{3}}+\frac{A_{4}}{x^{4}}+\frac{A_{5} \ln x}{x}, \\
& \sigma_{d f}(x)=\frac{\left(A_{1} x^{2}+A_{2} x+A_{3}\right)}{\left(A_{4}+x\right)^{4}} x^{A_{5}}
\end{aligned}
$$

where $d a$ stands for the dipole-allowed transitions and $d f$ for the dipole-forbidden ones, $x \equiv E / E_{t h}$ is the impact energy in units of the transition threshold, and $A_{1}$ to $A_{5}$ are the fitting coefficients. While the fitting formula of Eq. (5) for the dipole-allowed transitions is often encountered in the literature, that for the dipole-forbidden cross sections is introduced here for the first time. It is certainly possible to implement Eq. (5) without the logarithmic term to fit the dipole-forbidden cross sections; however, the use of Eq. (6) is made here to demonstrate the universal applicability of this formula which can also be used for spin-forbidden cross sections. Since the dipole-forbidden excitation cross section asymptotically decays as $\sigma_{d f}(E \rightarrow \infty) \sim 1 / E$, the coefficient $A_{5}$ in Eq. (6) was fixed to be 1 in this case. Tables I and II provide the fitting coefficients for all 72 cross sections calculated here.

In conclusion, the electron-impact excitation cross sections for transitions between all terms with principal quantum number $n \leq 4$ were calculated for Li-like ions of boron and beryllium with the convergent close-coupling, K-matrix, and Coulomb-Born-exchange methods. It was found that the K-matrix results generally agree with the CCC data within 20-30\%. The CCC cross sections, which are expected to be the most accurate, were fitted with formulas providing correct asymptotic energy dependence, and the fitting coefficients are tabulated. The results of the fitting can be used for various applications where a fast calculation of electron-impact excitation cross sections is required.

\section{Acknowledgements}

We are very grateful to K. Bartschat for providing the RMPS data and to D. Proselkov for discussions on fitting functions. This work was supported by the German-Israeli Project Cooperation (DIP) and the Israeli Science Foundation and in part (L.V.) by ISTC fund (project No 1785-01) and RBRF (project 0002-17825).

\section{References}

1. Berrington, K. A. and Clark, R. E. H., At. Plasma-Mater. Interaction Data Fusion 3, 87, IAEA, Vienna (1992).

2. Bartschat, K. and Bray, I., J. Phys. B 30, L109 (1997).

3. Marchalant, P. J., Bartschat, K. and Bray, I., J. Phys. B 30, L435 (1997).

4. Tsigutkin, K., Bernshtam, V., Ralchenko, Yu. V. and Maron, Y., in: 5th Israeli Conference on Plasma Science and Applications, Rehovot, Israel (2002).

5. Fisher, V. I. et al., Phys. Rev. A 55, 329 (1997).

6. Fisher, V. I. et al., Phys. Rev. A 56, 3726 (1997).

7. Schweinzer, J. et al., At. Data Nucl. Data Tables 72, 239 (1999).

8. Beigman, I. L. et al., At. Data Nucl. Data Tables 74, 123 (2000).

9. Bray, I., in: Proc. ICAMDATA - Second International Conf. (Edited by K. A. Berrington and K. L. Bell) (AIP Publishing, 2001) AIP Conference Proceedings v. 543, 178.

10. Bray, I. and Stelbovics, A. T., Adv. At. Mol. Opt. Phys. 35, 209 (1995).

11. Sobelman, I. I., Vainshtein, L. A. and Yukov, E. A., "Excitation of Atoms and Broadening of Spectral lines," (Springer-Verlag, Berlin/ New York, 1995).

12. Shevelko, V. P. and Vainshtein, L. A., "Atomic Physics for Hot Plasmas," (IOP Publishing Bristol, 1993).

13. Taylor, P. O., Phaneuf, R. A. and Dunn, G. H., Phys. Rev. A 22, 435 (1980).

14. Woitke, O. et al., Phys. Rev. A 58, 4512 (1998). 